\title{
Physical, Mechanical, and Thermal Analysis of Polylactic Acid/Fumed Silica/Clay (1.28E) Nanocomposites
}

\author{
Josephine Chang Hui Lai, ${ }^{1}$ Md. Rezaur Rahman, ${ }^{1}$ and Sinin Hamdan ${ }^{2}$ \\ ${ }^{1}$ Department of Chemical Engineering and Energy Sustainability, Faculty of Engineering, Universiti Malaysia Sarawak (UNIMAS), \\ 94300 Kota Samarahan, Sarawak, Malaysia \\ ${ }^{2}$ Department of Mechanical and Manufacturing Engineering, Faculty of Engineering, Universiti Malaysia Sarawak (UNIMAS), \\ 94300 Kota Samarahan, Sarawak, Malaysia
}

Correspondence should be addressed to Josephine Chang Hui Lai; josephinelai91@hotmail.com

Received 28 September 2015; Revised 9 December 2015; Accepted 10 December 2015

Academic Editor: Jean-Marc Saiter

Copyright (C) 2015 Josephine Chang Hui Lai et al. This is an open access article distributed under the Creative Commons Attribution License, which permits unrestricted use, distribution, and reproduction in any medium, provided the original work is properly cited.

Polylactic acid/fumed silica/clay (PLA/FS/clay) (1.28E) nanocomposites have been successfully prepared by solution-intercalation film-casting technique. The resultant nanocomposites were characterized by Fourier Transform Infrared Spectroscopy (FT-IR), Scanning Electron Microscopy (SEM), tensile test, thermogravimetric analysis (TGA), and moisture absorption test. The FT-IR spectrum indicated that PLA/FS/clay with $2 \mathrm{wt} \%$ had much broader peak compared to $5 \mathrm{wt} \%, 10 \mathrm{wt} \%$, and $15 \mathrm{wt} \%$ nanocomposites. Incorporation of clay (1.28E) with $2 \mathrm{wt} \%$ showed the best compatibility with PLA/FS matrix. PLA/FS/clay (1.28E) nanocomposite with $2 \mathrm{wt} \%$ of clay loading had higher tensile strength and modulus compared to other nanocomposites. The thermal stability and activation energy of $2 \mathrm{wt} \%$ of PLA/FS/clay (1.28E) nanocomposite are the highest among all the nanocomposites. The moisture absorbed into PLA/FS/clay (1.28E) nanocomposite was significantly reduced with clay loading of $2 \mathrm{wt} \%$.

\section{Introduction}

In recent years, biodegradable polymers have gained great attention from both academic and industrial researchers as they are one of the renewable materials with excellent characteristics such as biodegradability, biocompatibility, low toxicity, and low cost $[1,2]$. Besides, the green environment implemented worldwide encourages the usage of biodegradable polymers. Polylactic acid (PLA) is linear aliphatic thermoplastic polyester that can be synthesized from lactic acid monomer or by ring-opening polymerization of lactide monomers [3]. It is one of the biodegradable polymers with reasonably good mechanical properties that can be widely applied in agriculture, medical devices, packaging, and textiles [4].

Despite numerous advantages, pure PLA is unable to perform better due to its low draw ability [5] and insufficient toughness [6]. In order to improve the PLA properties, organic or inorganic fillers should be incorporated into polymer matrix which significantly enhances the mechanical properties. Fillers that are commonly introduced into polymer nanocomposites are fumed silica (FS) and nanoclay (clay). FS is filler that functioned as nucleation agent to improve the mechanical properties as well as the surface morphology [7]. It is a good alternative to incorporate FS as second filler because FS has large, uniform, and nonporous surface [8]. This will enhance strong interfacial bonding between FS nanoparticles and PLA matrix that leads to better polymer-particle interaction [9]. On the other hand, clay is introduced to enhance the reinforcement between the polymer matrix and fillers [10]. Besides, it also performs as a compatibilizer that aids to improve the bonding adhesion with the polymer matrix [11].

The effect of introducing FS into PLA matrix has been investigated. The addition of silica nanoparticles into PLA matrix can greatly improve the tensile strength and modulus value of the PLA-based composites [4]. In addition, the presence of FS in the polymer matrix does not only 
increase mechanical properties; it also enhances the heat resistance and reduces the gas permeability and flammability in comparison with the pure polymer or conventional PLA composites [12].

Apart from that, the influences of clay on the properties of PLA have also been examined. The clay is proven to be well intercalated with PLA to improve the properties of pure PLA [13]. From the past research, the tensile properties in the PLA nanocomposites increase with the addition of clay content up to $4 \mathrm{wt} \%$ [14]. Moreover, tensile strength, modulus, and elongation-at-break increase significantly due to the addition of clay to the PLA matrix [15]. However, natural clay is not encouraged to be used as it is hydrophilic. The hydrophilic clay will prevent clay delamination and reduce the intercalation of hydrophobic polymer chains into the gallery [16]. Thus, the clay is modified so that it is more compatible with common hydrophilic polymers. The most widely used cationic clay is montmorillonite due to its large cation exchange capacity [17]. Clay structure is consisting of interlayer caused by the van der Waals force between the layer gaps.

Ion exchange mechanism is one of the methods to prepare polymer nanocomposites. The hydrophilic clay surface is modified to become organophilic so that the PLA chains can be easily intercalated into the silicate galleries [18]. Cationic surfactant such as alkylammonium cations in the clay $(1.28 \mathrm{E})$ plays important role in the mechanism. It helps to lower the surface energy of inorganic host [19]. Besides, the wetting characteristics of the PLA matrix can be well improved. Thus, larger interlayer spacing can be achieved. In addition, alkylammonium cations provide functional groups such as $\mathrm{Si}$ at the end of the silicate layers to react with the hydroxyl groups of PLA matrix [20]. Therefore, the adhesion between polymer matrix and fillers can be greatly improved. Apart from that, FS is another type of filler that can be introduced into PLA/clay nanocomposites. Si group of FS creates strong covalent bonding with the oxides of PLA matrix inside the clay galleries [21]. This helps to improve the nanocomposites with strong bonding from the side chains of clay as well as in the clay galleries. Therefore, addition of FS and clay in the PLA matrix is another alternative that will significantly improve the physical, mechanical, thermal, and barrier properties as well as the surface morphology.

In the study, we aim at reporting on the preparation of PLA/FS/clay (1.28E) nanocomposites by solution intercalation film casting technique. Besides, the physical properties, surface morphology, and tensile properties of the $\mathrm{PLA} / \mathrm{FS} /$ clay (1.28E) nanocomposites are investigated.

\section{Experiment}

2.1. Materials. The silicon dioxide powder used was supplied by Sigma-Aldrich, United States. The particle size of silicon dioxide powder was less than 8 microns which was white to off-white in colour. The chemicals used, polylactic acid (PLA) and dichloromethane, were supplied by Merck Millipore. Nanoclay, Nanomer 1.28E, was supplied by Sigma-Aldrich. Nanomer $1.28 \mathrm{E}$ was montmorillonite clay surface that was modified by $25-30 \mathrm{wt} \%$ trimethyl stearyl ammonium. The
TABLE 1: Preparation of PLA/FS/clay (1.28E) nanocomposites.

\begin{tabular}{lcc}
\hline $\begin{array}{l}\text { Amount of polylactic } \\
\text { acid (PLA) (wt\%) }\end{array}$ & $\begin{array}{c}\text { Amount of fumed } \\
\text { silica (FS) (wt\%) }\end{array}$ & $\begin{array}{c}\text { Amount of } \\
\text { clay (wt\%) }\end{array}$ \\
\hline 97.8 & 0.2 & 2.0 \\
94.8 & 0.2 & 5.0 \\
89.8 & 0.2 & 10.0 \\
84.8 & 0.2 & 15.0 \\
\hline
\end{tabular}

bulk density of the clay was 200 to $500 \mathrm{~kg} / \mathrm{m}^{3}$ and average particle size was around 8 microns.

2.2. Solution-Intercalation Film-Casting Technique for Nanocomposites Preparation. PLA/FS/clay (1.28E) nanocomposites were prepared by using polylactic acid, fumed silica, and clay (1.28E) as shown in Table 1 . For each composition, $1 \mathrm{~g}$ of PLA was dissolved in $10 \mathrm{~mL}$ of dichloromethane. Clay dispersions were obtained by suspension of well-dried clay in a separate beaker of dichloromethane. Calculations for varying final composite compositions were based on inorganic component of the modified clay thereby excluding the amount of organic modifier. Both the PLA solution and clay suspension were sonicated separately for $30 \mathrm{~min}$ with an ultrasonicator at room temperature and subsequently mixed. Fumed silica was added before the final mixture and was further ultrasonicated for $30 \mathrm{~min}$. The mixture was then casted on a glass surface and kept in a desiccator for controlled evaporation of the solvent for 2 days. Optically clear nanocomposite films with thickness ranging from 500 to $700 \mu \mathrm{m}$ were obtained and subsequently dried at $80^{\circ} \mathrm{C}$ under vacuum for 2 days. The nanocomposites were kept in desiccator for further characterizations.

\subsection{Microstructural Analysis}

2.3.1. Fourier Transform Infrared Spectroscopy (FT-IR). The infrared spectra of the nanocomposites were recorded on a Shimadzu IRAffinity-1. The transmittance range of the scan was 600 to $4000 \mathrm{~cm}^{-1}$.

2.3.2. Scanning Electron Microscopy (SEM). The interfacial bonding between the polylactic acid, fumed silica, and clay (1.28E) was examined using a Scanning Electron Microscope (SEM) (JSM-6710F) supplied by JEOL Company Limited, Japan. The specimens were first fixed with Karnovsky's fixative and then taken through a graded alcohol dehydration series. Once dehydrated, the specimen was coated with a thin layer of gold before being viewed microscopically. The micrographs were taken at magnifications ranging from 250 to 1500 .

2.3.3. Tensile Testing. Mold shape thin films were cut with a rectangular die and tested in a Lloyd LRX $(2500 \mathrm{~N})$ materials testing machine at room temperature. The gauge length, width, and thickness of the samples were 25,4 , and $0.15 \mathrm{~mm}$, 


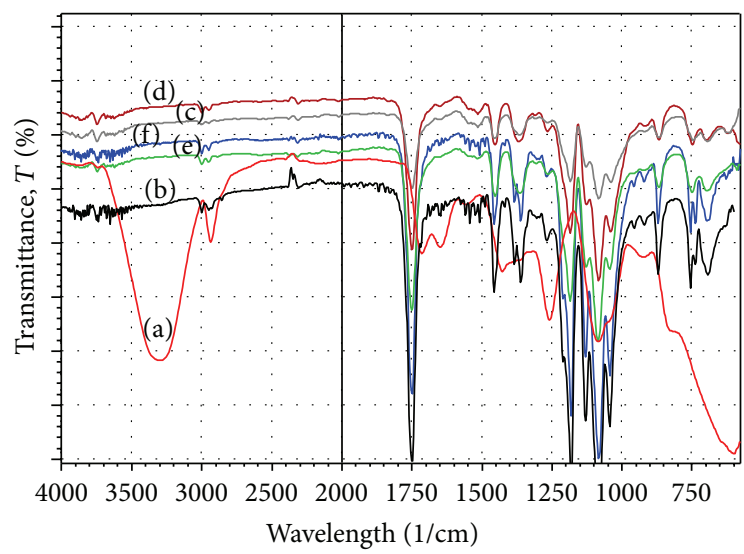

FIgURE 1: FT-IR spectra of (a) pure PLA, (b) PLA/FS, (c) $2 \mathrm{wt} \%$ of PLA/FS/clay (1.28E) nanocomposite, (d) $5 \mathrm{wt} \%$ of PLA/FS/clay (1.28E) nanocomposite, (e) $10 \mathrm{wt} \%$ of PLA/FS/clay (1.28E) nanocomposite, and (f) $15 \mathrm{wt} \%$ of PLA/FS/clay (1.28E) nanocomposite.

respectively. The cross head speed used was $1 \mathrm{~mm} / \mathrm{min}$. The quoted results were averaged over four specimens.
2.3.4. Thermogravimetric Analysis (TGA). Thermogravimetric analysis (TGA) measurements were carried out on 5$10 \mathrm{mg}$ of PLA/FS/clay (1.28E) nanocomposites at a heating rate of $10^{\circ} \mathrm{C} / \mathrm{min}$ in a nitrogen atmosphere using a Thermogravimetric Analyzer (TA Instrument SDT Q600). PLA/FS/clay (1.28E) nanocomposites were subjected to TGA in high purity nitrogen under a constant flow rate of $5 \mathrm{~mL} / \mathrm{min}$. Thermal decomposition of each sample occurred in a programmed temperature range of $0^{\circ} \mathrm{C}$ to $700^{\circ} \mathrm{C}$. The continuous weight loss and temperature were recorded and analyzed.

2.3.5. Moisture Absorption Test. The moisture absorption was carried out at $110^{\circ} \mathrm{C}$ for $3 \mathrm{~h}$ by using electronic moisture balance (MOC-120H) supplied by Shimadzu Corporation, Kyoto, Japan. Dry nanocomposites (dried at $25^{\circ} \mathrm{C}$ ) were immersed in distilled water, continued by removing and weighing process. The nanocomposites were placed in flat position into the tester during the measurement. The heater lid was then closed firmly and the display was switched from a display of the weight to a percentage display and the measuring time was displayed too. The moisture water absorbed, $W_{\mathrm{ab}}$, was calculated by using

$$
\begin{aligned}
& \text { Moisture absorbed percentage, } W_{\mathrm{ab}}(\%) \\
& =\frac{\text { Weight of wet nanocomposites }\left(W_{w}\right)-\text { weight of dry nanocomposites }\left(W_{d}\right)}{\text { weight of wet nanocomposites }\left(W_{w}\right)} \times 100 \text {. }
\end{aligned}
$$

\section{Results and Discussions}

\subsection{Fourier Transform Infrared Spectroscopy (FT-IR) Analysis.} The FT-IR analysis of pure PLA, PLA/FS, and PLA/FS/clay (1.28E) nanocomposites was shown in Figure 1. The peaks from 3000 to $3500 \mathrm{~cm}^{-1}$ corresponded to the stretching modes and absorption of water molecules, while the band at $2930 \mathrm{~cm}^{-1}$ was attributed to C-H interaction with the surface of the PLA [22]. The peak at $1750 \mathrm{~cm}^{-1}$ was ascribed to $\mathrm{C}=\mathrm{O}$ stretching of the nanocomposites which was detected at a lower frequency. $2 \mathrm{wt} \%$ of PLA/FS/clay (1.28E) nanocomposite had lower transmittance peak at $1750 \mathrm{~cm}^{-1}$ due to hydrogen bonding interactions with surface silanols [23]. The sharp absorption band at $1100 \mathrm{~cm}^{-1}$ indicated the silica nanoparticles generation with $\mathrm{Si}-\mathrm{O}-\mathrm{Si}$ stretching mode as a result of existing silica containing minerals within the PLA/clay matrix $[22,24]$.

According to Figure 2, the hydroxyl groups from PLA were removed throughout the ion exchange mechanism with no significant peaks at $190^{\circ} \mathrm{C}[18-20,25]$. PLA/FS/clay (1.28E) nanocomposites with different weight percentages of clay reduced hydroxyl group and improved the intercalation between the clay and PLA/FS matrix [26]. Overall, $2 \mathrm{wt} \%$ of PLA/FS/clay (1.28E) nanocomposite showed broader peaks compared to pure PLA, PLA/FS, $5 \mathrm{wt} \%, 10 \mathrm{wt} \%$, and $15 \mathrm{wt} \%$ of PLA/FS/clay (1.28E) nanocomposites. Higher clay weight percentage led to sharp peaks which reduced the compatibility between clay and PLA/FS matrix. Therefore, $2 \mathrm{wt} \%$ of clay (1.28E) was proven to be the optimum weight percentage that would be introduced into PLA/FS matrix to form PLA/FS/clay (1.28E) nanocomposites.

3.2. Surface Morphology Analysis. SEM was used to investigate the interfacial bonding between the clay and PLA/FS matrix. Figures 3(a)-3(f) presented the SEM images of pure PLA, PLA/FS, $2 \mathrm{wt} \%, 5 \mathrm{wt} \%, 10 \mathrm{wt} \%$, and $15 \mathrm{wt} \%$ of PLA/FS/clay (1.28E) nanocomposites. From Figure 3(a), there were many tiny pores detected on the surface morphology of pure PLA due to the hydroxyl groups in PLA matrix [27]. Besides, Figure 3(b) showed linkage between PLA matrix and FS but there was some aggregation detected on the surface of PLA/FS nanocomposites. In addition, the uniform dispersion of $2 \mathrm{wt} \%$ and $5 \mathrm{wt} \%$ of clay (1.28E) onto PLA/FS matrix proved the compatibility between PLA/FS matrix and clay, as shown in Figures 3(c) and 3(d). The delamination and good dispersion of clay (1.28E) within PLA matrix had enhanced the Si-O-Si bonding. The strong SiO-Si bonding was proven in FT-IR results [28]. Besides, nanoscale silica particles ensured a large specific surface allowing greater surface interaction for the nanocomposites [29]. This improved PLA matrix with stronger interfacial bonding within the nanocomposites. Figure 3(e) showed some agglomeration on the surface of $10 \mathrm{wt} \%$ of PLA/FS/clay 


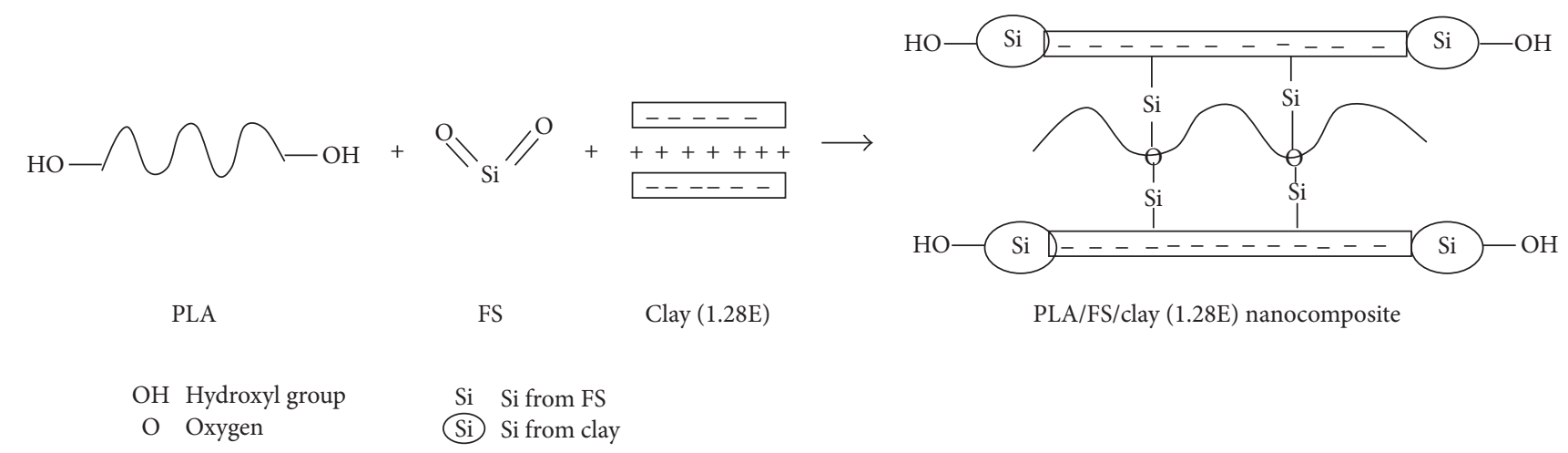

FIGURE 2: The formation of PLA/FS/clay (1.28E) nanocomposite by ion exchange mechanism.

(1.28E) nanocomposite, due to the aggregation of FS in the interspherulitic region. From Figure 3(f), it could be observed that $15 \mathrm{wt} \%$ of PLA/FS/clay (1.28E) nanocomposite had poor surface dispersion in the presence of agglomeration due to high surface energy and poor adhesion between clay and PLA/FS matrix. The poor compatibility of PLA/FS matrix with clay $(1.28 \mathrm{E})$ at higher clay weight percentage occurred as the inert surface of PLA/FS could not react well with the clay particles [30]. Therefore, $2 \mathrm{wt} \%$ of PLA/FS/clay (1.28E) nanocomposite showed better interfacial bonding and strong compatibility among all the nanocomposites which was reflected in the improvement of the tensile properties.

3.3. Tensile Testing. The tensile strength and modulus of pure PLA, PLA/FS, and PLA/FS/clay (1.28E) nanocomposites were shown in Figure 4. Pure PLA had the lowest tensile strength and modulus due to the weak bonding between the particles in the matrix. FS was functioned as nucleation agent improved the tensile strength and modulus of the PLA/FS nanocomposite compared to PLA matrix [7]. $2 \mathrm{wt} \%$ of PLA/FS/clay (1.28E) nanocomposite had the highest tensile strength and modulus among all different clay weight percentages of PLA/FS/clay nanocomposites. It showed that the tensile strength increased when $2 \mathrm{wt} \%$ of clay was added to the PLA/FS matrix as clay (1.28E) contained octadecylamine which improved the miscibility of clay and PLA system. Aggregation of $2 \mathrm{wt} \%$ of clay $(1.28 \mathrm{E})$ would reduce the interparticle distance between PLA/FS matrix and clay and thus the tensile strength and modulus of the nanocomposites [31]. However, as shown in Figure 4, the tensile strength could not be further improved with higher clay weight percentages due to the relatively large size dispersed phases of clay (1.28E) which led to weak interfacial adhesion of the PLA/FS matrix [32]. In addition, the improvement in the interfacial bonding was clearly shown in Figure 4 due to better stress transfer efficiency from matrix to clay, which was attributed to the alkyl chains on the surface of FS/clay [33]. This proved that the $2 \mathrm{wt} \%$ of clay (1.28E) added to PLA/FS system increased compatibility, which enhanced the tensile strength and modulus, as reflected in the surface morphology.

3.4. Thermogravimetric Analysis (TGA). TGA was carried out to investigate the importance of the influence of fumed silica and clay on the thermal degradation of PLA/FS/clay (1.28E) nanocomposites was analyzed. Two stages of thermal decomposition were detected in the thermal decomposition of PLA/FS/clay (1.28E) nanocomposites, namely, the moisture loss of trapped solvent (below $300^{\circ} \mathrm{C}$ ) and polylactic acid residues degradation above $300^{\circ} \mathrm{C}$ [34].

According to Figure 5, it showed that the first step degradation occurred at about $250^{\circ} \mathrm{C}$ to $300^{\circ} \mathrm{C}$ while the second step degradation occurred at above $350^{\circ} \mathrm{C}$ for all the nanocomposites. It was detected that the weight percent loss on first stage is $14.9 \%, 11.9 \%, 3.8 \%, 6.7 \%, 8.7 \%$, and 9.1\% for the pure PLA, PLA/FS, $2 \mathrm{wt} \%$, $5 \mathrm{wt} \%, 10 \mathrm{wt} \%$, and $15 \mathrm{wt} \%$ of the PLA/FS/clay (1.28E) nanocomposites as absorbed water on the nanocomposite surface was removed through dehydration process. During second stage of thermal decomposition, $2 \mathrm{wt} \%$ of PLA/FS/clay (1.28E) nanocomposite showed the lowest weight percent loss (81.0\%) among all the nanocomposites while weight percent loss of pure PLA, PLA/FS, $5 \mathrm{wt} \%, 10 \mathrm{wt} \%$, and $15 \mathrm{wt} \%$ of PLA/FS/clay (1.28E) nanocomposites was about 93.8\%, 86.3\%, 83.8\%, 83.9\%, and $88.4 \%$ as shown in Figure 5. The improved thermal stability of the $2 \mathrm{wt} \%$ of PLA/FS/clay (1.28E) nanocomposite was attributed to the clay acting as compatibilizer [35] and insulating barrier [36] that retarded the motion of polymer chain. It was concluded that the introduction of $2 \mathrm{wt} \%$ of clay (1.28E) as nanofillers was compatible with PLA/FS matrix and thus increased the thermal stability of PLA/FS/clay (1.28E) nanocomposites.

Table 2 showed the activation energy which could be helpful in reaching conclusions about the thermal stability of PLA/FS/clay (1.28E) nanocomposites. Arrhenius equation was used to determine the activation energy [37]. It was found that the activation energy of $2 \mathrm{wt} \%$ of PLA/FS/clay (1.28E) nanocomposite was significantly higher than pure PLA, PLA/FS, $5 \mathrm{wt} \%, 10 \mathrm{wt} \%$, and $15 \mathrm{wt} \%$ of PLA/FS/clay (1.28E) nanocomposites. $2 \mathrm{wt} \%$ of clay (1.28E), PLA/FS matrix provided a barrier effect on the surface of the nanocomposites which cause the confinement of the degrading nanocomposites [38]. Besides, physical-chemical adsorption of surface modified clay (1.28E) at $2 \mathrm{wt} \%$ would delay the volatilization of the nanocomposites [39].

Overall, the incorporation of $2 \mathrm{wt} \%$ of clay $(1.28 \mathrm{E})$ PLA/FS matrix successfully improved thermal stability of 


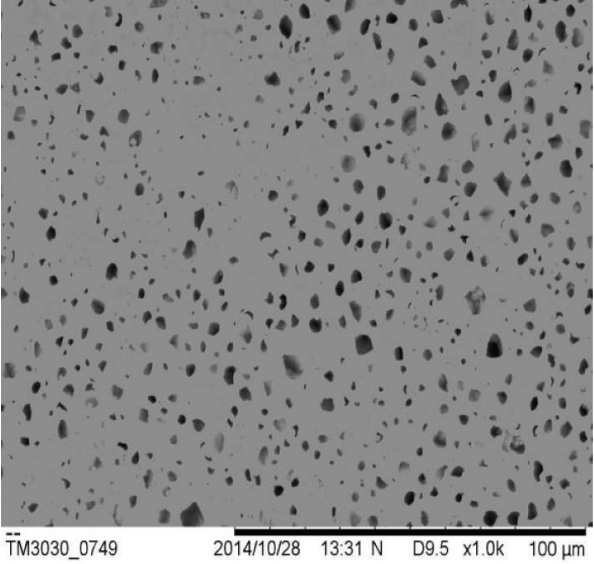

(a)

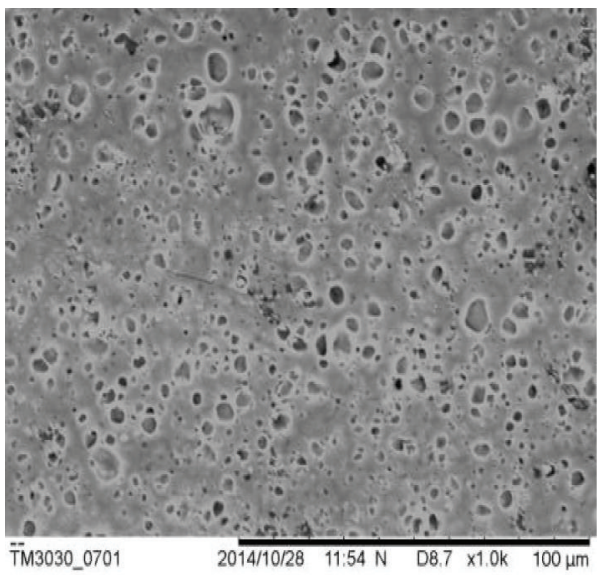

(c)

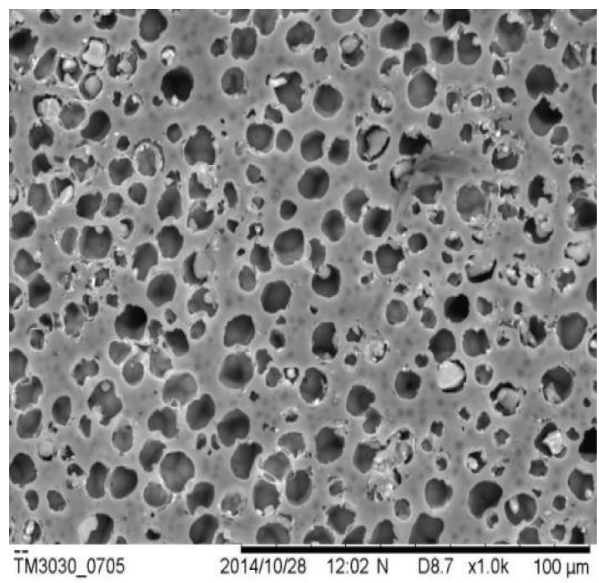

(e)

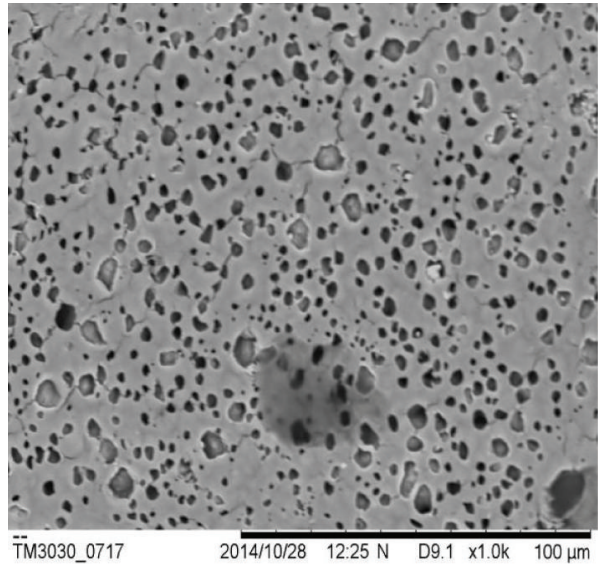

(b)

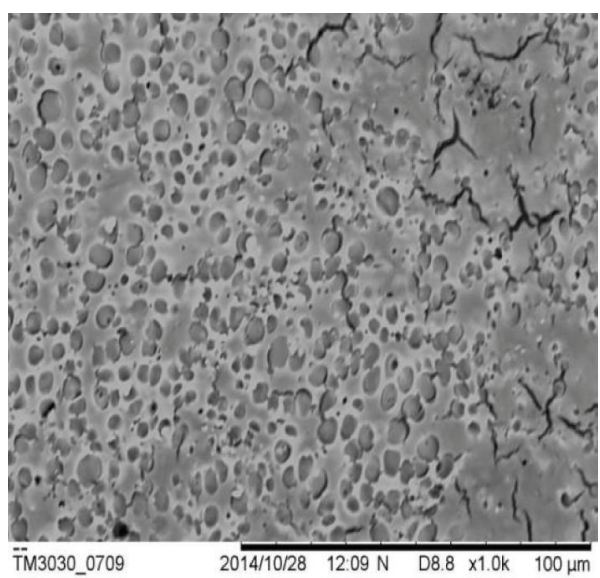

(d)

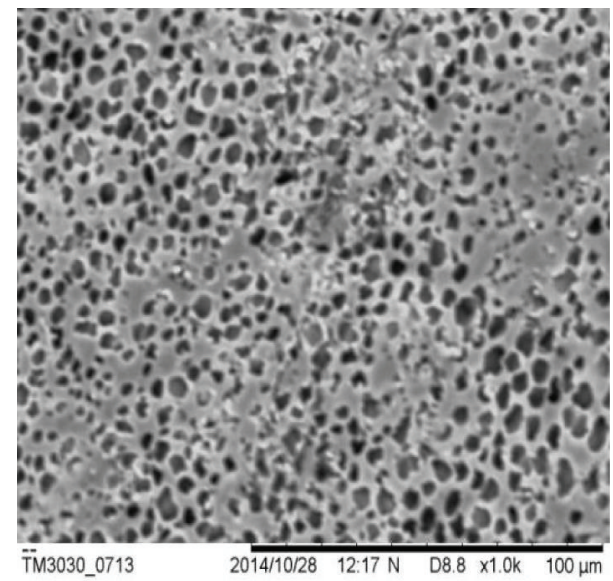

(f)

Figure 3: SEM micrographs of (a) pure PLA, (b) PLA/FS, (c) 2 wt\% of PLA/FS/clay (1.28E) nanocomposite, (d) 5 wt $\%$ of PLA/FS/clay (1.28E) nanocomposite, (e) $10 \mathrm{wt} \%$ of PLA/FS/clay (1.28E) nanocomposite, and (f) $15 \mathrm{wt} \%$ of PLA/FS/clay (1.28E) nanocomposite.

PLA/FS/clay (1.28E) nanocomposites that was proven by physical and mechanical results.

3.5. Moisture Absorption Analysis. Moisture absorption of the pure PLA, PLA/FS, and PLA/FS/clay (1.28E) nanocomposites with four different clay weight percentages ( $2 \mathrm{wt} \%, 5 \mathrm{wt} \%$, $10 \mathrm{wt} \%$, and $15 \mathrm{wt} \%$ ) was investigated by using Fick's law. All PLA/FS/clay nanocomposites showed a sharp increment of moisture absorption at the first 15 minutes and remained constant for 75 minutes. From Figure 6,2 wt $\%$ of PLA/FS/clay 
TABLE 2: Activation energy of PLA/FS/clay (1.28E) nanocomposites determined by using Arrhenius equation.

\begin{tabular}{|c|c|c|c|c|c|c|c|}
\hline Samples & $T_{i}\left({ }^{\circ} \mathrm{C}\right)^{\mathrm{a}}$ & $T_{m}\left({ }^{\circ} \mathrm{C}\right)^{\mathrm{b}}$ & $T_{f}\left({ }^{\circ} \mathrm{C}\right)^{\mathrm{c}}$ & $W_{T_{i}}(\%)^{\mathrm{d}}$ & $W_{T_{m}}\left({ }^{\circ} \mathrm{C}\right)^{\mathrm{e}}$ & $W_{T_{f}}\left({ }^{\circ} \mathrm{C}\right)^{\mathrm{f}}$ & $\begin{array}{c}\text { Activation energy, } \\
E_{a}(\mathrm{~kJ} / \mathrm{mol})\end{array}$ \\
\hline Pure PLA & 88.9 & 249.5 & 344.6 & 85.1 & 52.8 & 1.3 & 1006.24 \\
\hline PLA/FS nanocomposite & 90.5 & 250.1 & 354.1 & 88.1 & 55.9 & 1.8 & 1075.96 \\
\hline $2 \mathrm{wt} \%$ of PLA/FS/clay (1.28E) nanocomposite & 108.9 & 316.6 & 421.1 & 96.2 & 80.4 & 15.2 & 6670.45 \\
\hline $5 \mathrm{wt} \%$ of PLA/FS/clay (1.28E) nanocomposite & 95.3 & 313.7 & 419.3 & 93.2 & 73.0 & 9.5 & 3163.45 \\
\hline $10 \mathrm{wt} \%$ of PLA/FS/clay (1.28E) nanocomposite & 91.4 & 250.3 & 364.9 & 91.6 & 65.9 & 7.8 & 1946.78 \\
\hline $15 \mathrm{wt} \%$ of PLA/FS/clay (1.28E) nanocomposite & 91.2 & 250.1 & 355.4 & 90.9 & 65.2 & 2.5 & 1083.94 \\
\hline
\end{tabular}

${ }^{a}$ Temperature corresponding to the beginning of decomposition.

${ }^{\mathrm{b}}$ Temperature corresponding to the maximum rate of weight loss.

${ }^{\mathrm{c}}$ Temperature corresponding to the end of decomposition.

${ }^{\mathrm{d}}$ Mass loss at temperature corresponding to the beginning of decomposition.

${ }^{\mathrm{e}}$ Mass loss at temperature corresponding to the maximum rate of weight loss.

${ }^{\mathrm{f}}$ Mass loss at temperature corresponding to the end of decomposition.

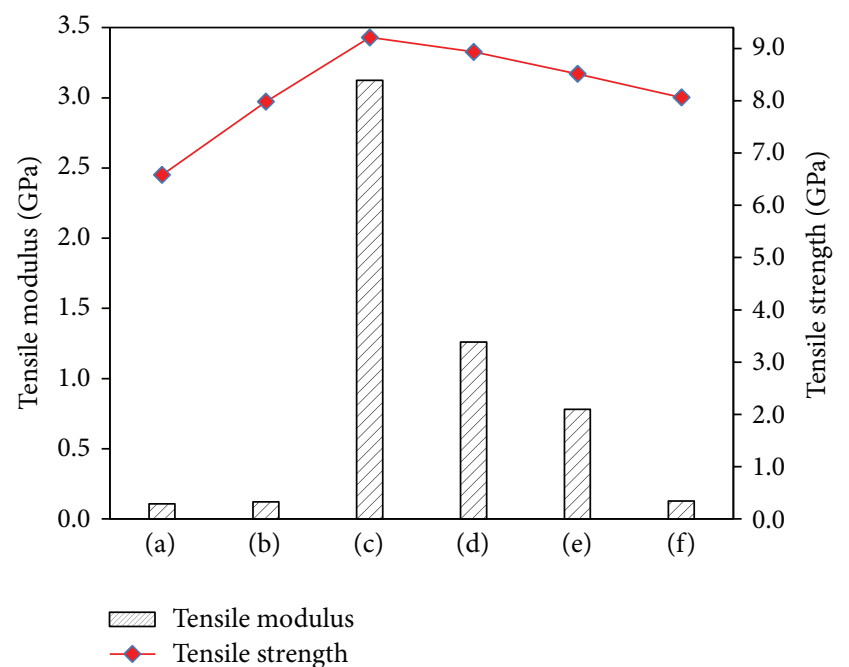

Figure 4: Tensile strength and modulus of (a) pure PLA, (b) PLA/FS, (c) $2 \mathrm{wt} \%$ of PLA/FS/clay (1.28E) nanocomposite, (d) $5 \mathrm{wt} \%$ of PLA/FS/clay (1.28E) nanocomposite, (e) $10 \mathrm{wt} \%$ of PLA/FS/clay (1.28E) nanocomposite, and (f) $15 \mathrm{wt} \%$ of PLA/FS/clay (1.28E) nanocomposite.

(1.28E) nanocomposite showed significantly lower moisture absorption weight $(<2.0 \%)$ compared to pure PLA, PLA/FS, $5 \mathrm{wt} \%, 10 \mathrm{wt} \%$, and $15 \mathrm{wt} \%$ of the nanocomposites. Strong covalent bonding formed between PLA/FS matrix and clay (1.28E) reduced the pore size on the surface of the nanocomposites. This led to narrow water diffusion pathway and thus the water sensitivity greatly decreased. Besides, $2 \mathrm{wt} \%$ of clay (1.28E) acted as insulating barrier against the moisture diffusion into the PLA/FS matrix [40]. This proved that $2 \mathrm{wt} \%$ of clay (1.28E) was well intercalated with PLA/FS matrix which enhanced mechanical properties as well as thermal properties of the nanocomposites.

\section{Conclusions}

Pure PLA, PLA/FS, and PLA/FS/clay (1.28E) nanocomposites with different four clay weight percentages $(2 \mathrm{wt} \%, 5 \mathrm{wt} \%$,

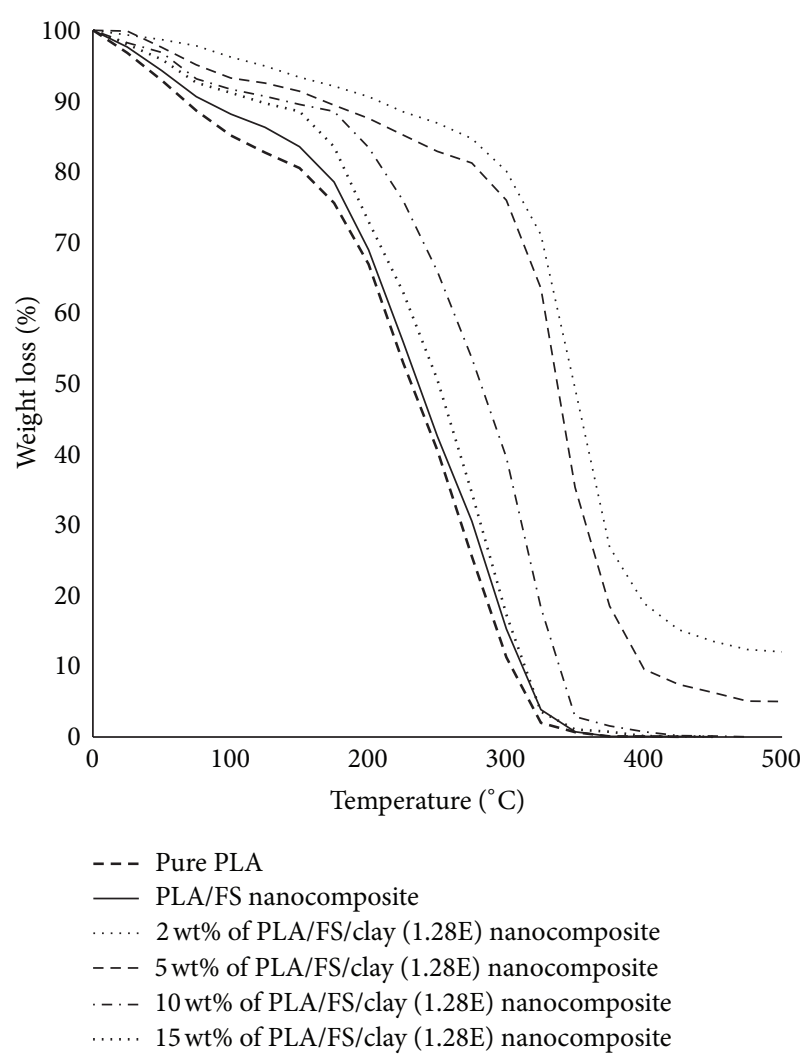

FIGURE 5: TGA curves for PLA/FS/clay (1.28E) nanocomposites.

$10 \mathrm{wt} \%$, and $15 \mathrm{wt} \%$ ) were prepared via solution intercalation method. FT-IR spectrum showed that the hydroxyl groups were removed with the addition of clay $(1.28 \mathrm{E})$ at $2 \mathrm{wt} \%$ into PLA/FS matrix. $2 \mathrm{wt} \%$ of PLA/FS/clay (1.28E) nanocomposite showed the best surface morphology which proved $2 \mathrm{wt} \%$ of clay (1.28E) provided better compatibility with PLA/FS matrix. Besides, $2 \mathrm{wt} \%$ of PLA/FS/clay (1.28E) nanocomposite had higher tensile strength and modulus followed by PLA/FS/clay (1.28E), 5 wt $\%, 10$ wt $\%, 15$ wt $\%$, PLA/FS nanocomposites, and pure PLA, respectively. In addition, 


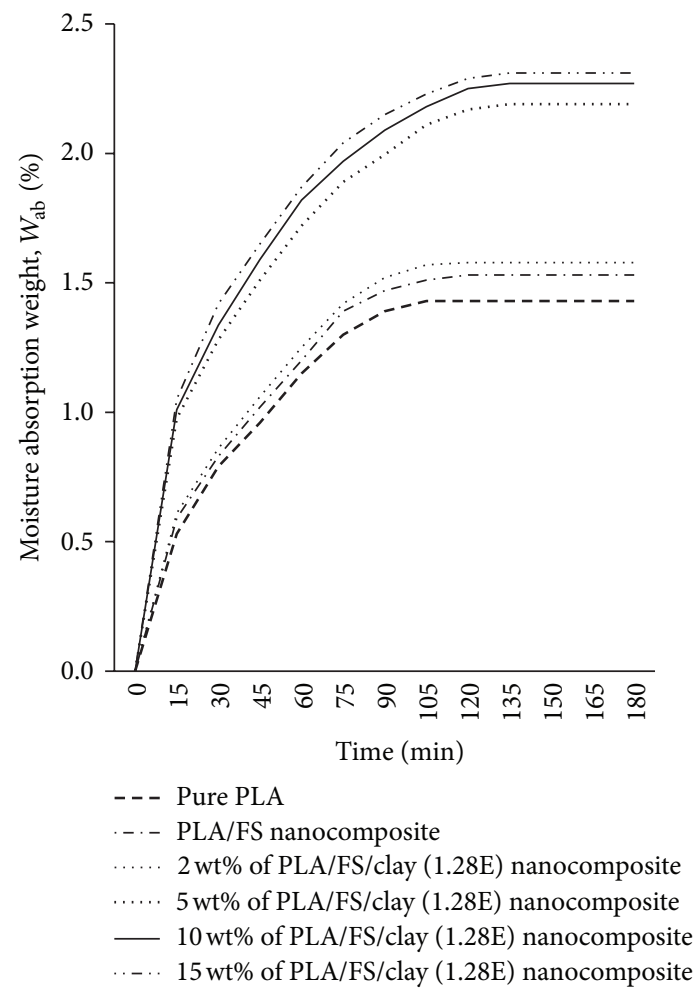

FIGURE 6: Moisture absorption curves of PLA/FS/clay (1.28E) nanocomposites.

addition of $2 \mathrm{wt} \%$ of clay (1.28E) PLA/FS matrix improved thermal stability of the nanocomposites and reduced the moisture weight percentage to be diffused into the nanocomposites. The addition of clay (1.28E) into PLA/FS matrix would significantly increase the potential of PLA nanocomposites to be applied in biomedical application.

\section{Conflict of Interests}

The authors declare that there is no conflict of interests regarding the publication of this paper.

\section{Acknowledgment}

The authors would like to acknowledge the Ministry of Higher Education Malaysia, for their financial support, Grant no. F02(DPP40)/1260/2015(15).

\section{References}

[1] S. Mecking, "Nature or petrochemistry-biologically degradable materials," Angewandte Chemie-International Edition, vol. 43, no. 9, pp. 1078-1085, 2004.

[2] A. K. Mohanty, M. Misra, and L. T. Drzal, "Sustainable biocomposites from renewable resources: opportunities and challenges in the green materials world," Journal of Polymers and the Environment, vol. 10, no. 1-2, pp. 19-26, 2002.

[3] D. Bikiaris, "Can nanoparticles really enhance thermal stability of polymers? Part II: an overview on thermal decomposition of polycondensation polymers," Thermochimica Acta, vol. 523, no. 1-2, pp. 25-45, 2011.

[4] I. R. Mustapa, R. A. Shanks, and I. Kong, "Poly(lactic acid)hemp-nanosilica hybrid composites: thermomechanical, thermal behavior and morphological properties," International Journal of Automotive Engineering and Technologies, vol. 3, no. 1, pp. 192-199, 2013.

[5] M. Baiardo, G. Frisoni, M. Scandola et al., "Thermal and mechanical properties of plasticized poly(L-lactic acid)," Journal of Applied Polymer Science, vol. 90, no. 7, pp. 1731-1738, 2003.

[6] L. Jiang, J. Zhang, and M. P. Wolcott, "Comparison of polylactide/nano-sized calcium carbonate and polylactide/ montmorillonite composites: Reinforcing effects and toughening mechanisms," Polymer, vol. 48, no. 26, pp. 7632-7644, 2007.

[7] S. H. Myoung, S. S. Im, and S. H. Kim, "Non-isothermal crystallization behavior of PLA/acetylated cellulose nanocrystal/silica nanocomposites," Polymer International, vol. 65, no. 1, pp. 115124, 2016.

[8] R. Khankrua, S. Pivsa-Art, H. Hiroyuki, and S. Suttiruengwong, "Thermal and mechanical properties of biodegradable polyester/silica nanocomposites," Energy Procedia, vol. 34, pp. 705-713, 2013.

[9] O. Bera, B. Pilić, J. Pavličević et al., "Preparation and thermal properties of polystyrene/silica nanocomposites," Thermochimica Acta, vol. 515, no. 1-2, pp. 1-5, 2011.

[10] D. E. Martínez-Tong, A. S. Najar, M. Soccio et al., "Quantitative mapping of mechanical properties in polylactic acid/natural rubber/organoclay bionanocomposites as revealed by nanoindentation with atomic force microscopy," Composites Science and Technology, vol. 104, pp. 34-39, 2014.

[11] B. Ayana, S. Suin, and B. B. Khatua, "Highly exfoliated ecofriendly thermoplastic starch (TPS)/poly (lactic acid)(PLA)/ clay nanocomposites using unmodified nanoclay," Carbohydrate Polymers, vol. 110, pp. 430-439, 2014.

[12] K. Fukushima, D. Tabuani, C. Abbate, M. Arena, and P. Rizzarelli, "Preparation, characterization and biodegradation of biopolymer nanocomposites based on fumed silica," European Polymer Journal, vol. 47, no. 2, pp. 139-152, 2011.

[13] S. S. Ray, K. Yamada, M. Okamoto, and K. Ueda, "Polylactidelayered silicate nanocomposite: a novel biodegradable material," Nano Letters, vol. 2, no. 10, pp. 1093-1096, 2002.

[14] M. Jollands and R. K. Gupta, "Effect of mixing conditions on mechanical properties of polylactide/montmorillonite clay nanocomposites," Journal of Applied Polymer Science, vol. 118, no. 3, pp. 1489-1493, 2010.

[15] A. Hasook, S. Tanoue, Y. Lemoto, and T. Unryu, "Characterization and mechanical properties of poly(lactic acid)/poly $(\varepsilon$ caprolactone)/organoclay nanocomposites prepared by melt compounding," Polymer Engineering and Science, vol. 46, no. 8, pp. 1001-1007, 2006.

[16] M.-A. Paul, M. Alexandre, P. Degée, C. Calberg, R. Jérôme, and P. Dubois, "Exfoliated polylactide/clay nanocomposites by insitu coordination-insertion polymerization," Macromolecular Rapid Communications, vol. 24, no. 9, pp. 561-566, 2003.

[17] S. H. Tabatabaei and A. Ajji, "Orientation, mechanical, and optical properties of poly (lactic acid) nanoclay composite films," Polymer Engineering and Science, vol. 51, no. 11, pp. 21512158, 2011.

[18] M. Faiz and M. Yatim, A Study of Interlayer Gallery of Modified Sodium Montmorillonite (MMT) Nanofiller Using Ion Exchange and Surfactant Method, Universiti Malaysia Pahang, Pahang, Malaysia, 2012. 
[19] S. S. Ray and M. Okamoto, "Polymer/layered silicate nanocomposites: a review from preparation to processing," Progress in Polymer Science, vol. 28, no. 11, pp. 1539-1641, 2003.

[20] S. Granick, Ed., Polymers in Confined Environments, Springer, New York, NY, USA, 1999.

[21] P. Thissen, O. Seitz, and Y. J. Chabal, "Wet chemical surface functionalization of oxide-free silicon," Progress in Surface Science, vol. 87, no. 9-12, pp. 272-290, 2012.

[22] O. M. Sadek, S. M. Reda, and R. K. Al-Bilali, "Preparation and characterization of silica and clay-silica core-shell nanoparticles using sol-gel method," Advances in Nanoparticles, vol. 2, no. 2, pp. 165-175, 2013.

[23] P. E. Poston, D. Rivera, R. Uibel, and J. M. Harris, "In situ detection of adsorbates at silica/solution interfaces by Fourier transform infrared attenuated total reflection spectroscopy using a silica-coated internal reflection element," Applied Spectroscopy, vol. 52, no. 11, pp. 1391-1398, 1998.

[24] Z. Al-Qodah and R. Shawabkah, "Production and characterization of granular activated carbon from activated sludge," Brazilian Journal of Chemical Engineering, vol. 26, no. 1, pp. 127136, 2009.

[25] W. S. N. Wan Kamaruzaman, A. H. Abdullah, and K. Yusoh, A Study of Morphological and Thermal Properties of PLAModified MMT (Ion Exchange Method) Nanocomposite, Universiti Malaysia Pahang, Pahang, Malaysia, 2013.

[26] J. Henderson, The Science and Archaeology of Materials, Psychology Press, East Sussex, UK, 2000.

[27] Y. Hong, C. Gao, Y. Shi, and J. Shen, "Preparation of porous polylactide microspheres by emulsion-solvent evaporation based on solution induced phase separation," Polymers for Advanced Technologies, vol. 16, no. 8, pp. 622-627, 2005.

[28] Kusmono and Z. A. M. Ishak, "Effect of clay addition on mechanical properties of unsaturated polyester/glass fiber composites,' International Journal of Polymer Science, vol. 2013, Article ID 797109, 7 pages, 2013.

[29] F. A. dos Santos and M. I. B. Tavares, "Development and characterization of hybrid materials based on biodegradable PLA matrix, microcrystalline cellulose and organophilic silica," Polimeros, vol. 24, no. 5, pp. 561-566, 2014.

[30] Y. Luo, Y. Zhao, J. Cai, Y. Duan, and S. Du, "Effect of aminofunctionalization on the interfacial adhesion of multi-walled carbon nanotubes/epoxy nanocomposites," Materials and Design, vol. 33, no. 1, pp. 405-412, 2012.

[31] J. Jordan, K. I. Jacob, R. Tannenbaum, M. A. Sharaf, and I. Jasiuk, "Experimental trends in polymer nanocomposites-a review," Materials Science and Engineering A, vol. 393, no. 1-2, pp. 1-11, 2005.

[32] K. Zhang, V. Nagarajan, M. Misra, and A. K. Mohanty, "Supertoughened renewable PLA reactive multiphase blends system: phase morphology and performance," ACS Applied Materials and Interfaces, vol. 6, no. 15, pp. 12436-12448, 2014.

[33] M. N. Islam, M. M. Haque, and M. M. Huque, "Mechanical and morphological properties of chemically treated coir-filled polypropylene composites," Industrial and Engineering Chemistry Research, vol. 48, no. 23, pp. 10491-10497, 2009.

[34] L. Jiang, J. Zhang, and M. P. Wolcott, "Comparison of polylactide/nano-sized calcium carbonate and polylactide/ montmorillonite composites: reinforcing effects and toughening mechanisms," Polymer, vol. 48, no. 26, pp. 7632-7644, 2007.

[35] D. Ji, Z. Liu, X. Lan, F. Wu, B. Xie, and M. Yang, "Morphology, rheology, crystallization behavior and mechanical properties of poly(lactic acid)/poly(butylene succinate)/dicumyl peroxide reactive blends," Journal of Applied Polymer Science, vol. 131, no. 3, Article ID 39580, 2014.

[36] E. Kontou, M. Niaounakis, and P. Georgiopoulos, "Comparative study of PLA nanocomposites reinforced with clay and silica nanofillers and their mixtures," Journal of Applied Polymer Science, vol. 122, no. 3, pp. 1519-1529, 2011.

[37] C. V. Chanmal and J. P. Jog, "Dielectric relaxations in PVDF/ $\mathrm{BaTiO}_{3}$ nanocomposites," eXPRESS Polymer Letters, vol. 2, no. 4, pp. 294-301, 2008.

[38] B. N. Jang, M. Costache, and C. A. Wilkie, "The relationship between thermal degradation behavior of polymer and the fire retardancy of polymer/clay nanocomposites," Polymer, vol. 46, no. 24, pp. 10678-10687, 2005.

[39] H. Palza and M. Yazdani-Pedram, "Effect of the hierarchical structure in poly(propylene)/clay composites on their thermal stability: from single- to multi-step degradation processes," Macromolecular Materials and Engineering, vol. 295, no. 1, pp. 48-57, 2010.

[40] A. Tcherbi-Narteh, M. V. Hosur, S. Zainuddin, and S. Jeelani, "Compression and flexural response of carbon/epoxy-nanoclay nanocomposites subjected to UV radiation and condensation," in Proceedings of the ASME International Mechanical Engineering Congress and Exposition, pp. 163-172, ASME, British Columbia, Canada, November 2010. 

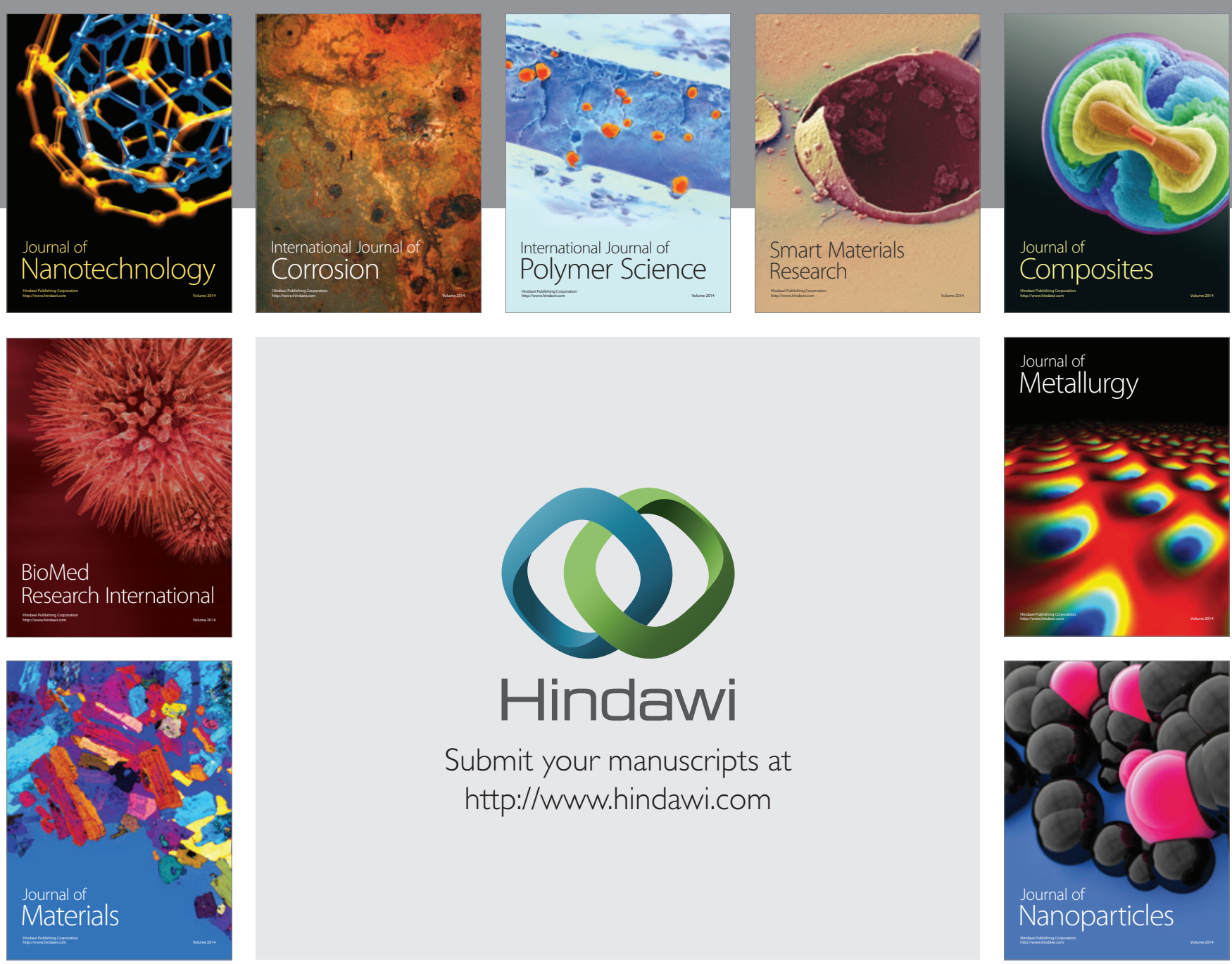

Submit your manuscripts at http://www.hindawi.com
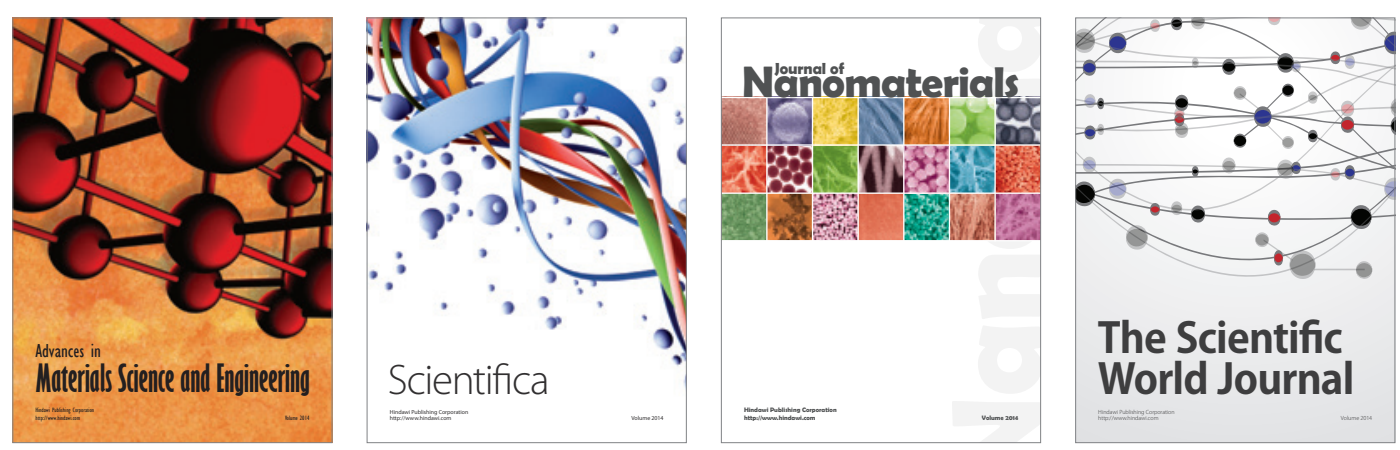

\section{The Scientific World Journal}
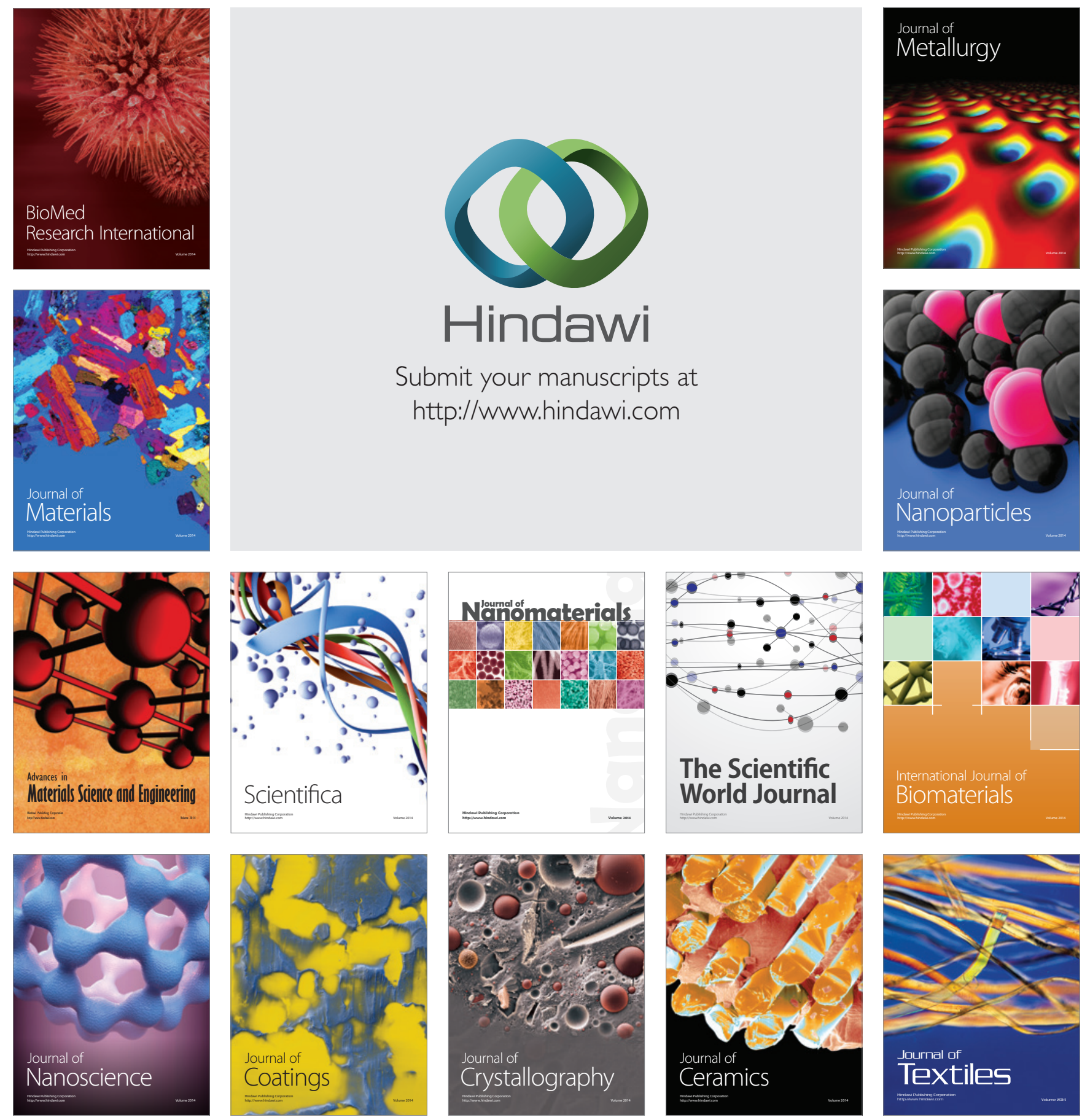